\title{
Ecologia das doenças infecciosas e parasitárias
}

\section{Fernando Dias de Ávila-Pires*}

O homem ocupa, indiscutivelmente, um lugar de destaque na natureza. A possibilidade de investigar, racionalizar, abstrair, construir modelos teóricos e de registrar e transferir a outras gerações a experiência individual e social acumulada constitui um mecanismo exclusivo de herança não-genética, o qual lhe permitiu elevar-se muito acima das demais espécies com que convive na biosfera.

Não está, contudo, longe de seus antepassados, - que revela na sua constituição biológica e demonstra no instinto primitivo de agressão, o qual, segundo alguns etologistas, constituiu o fator primordial de sua evolução, durante a fase de diferenciação incipiente. Sua atitude frente aos fenômenos naturais, como a doença, é de violência cega e irracional: "luta" contra a peste, "combate" a tuberculose e "move guerra" aos patógenos e seus vetores.

Racionalmente, o homem compreende que é um elemento integrante do grande ciclo biogeoquímico da biosfera, mas, em geral, age como se fora o centro do universo.

Do ponto de vista ecológico, o domínio da terra pelo homem constituiu um problema para as demais espécies. Nos últimos cem anos ele adquiriu o poder de influir, decisivamente, na constituição e equilíbrio dos ecossistemas, de alterar os padrōes de distribuição biogeográfica de macro e microorganismos, e de alterar o ritmo dos processos de evoluçã̃o da crosta terrestre e da biosfera. Erosão, poluição e extinção de espécies de plantas e animais constituem fenômenos naturais. Mas sua desorganização e aceleração, como subproduto das atividades humanas e, em especial, do ritmo do progresso tecnológico acelerado, comprometem a estabilidade do sistema ecológico de maneira irreversível.

A colonizaçāo tem-se revelado um processo desordenado de desagregação de ecossistemas nativos e de imposição de modelos que não levam em conta peculiaridades regionais e vocaçōes ecológicas. As alterações que o homem introduz nessas áreas abrem caminho à adaptação de espécies silvestres às condições domiciliares e ruderais. A fauna comensal e doméstica eleva o potencial trófico local e estimula o incremento de populaçōes de vetores e parasitos. E as facilidades de transporte e comunicação facilitam a expansão das áreas de distribuição das grandes endemias. 
Se o "homem tecnológico" controla os fatores do clima, do substrato e da biota que o cerca e é um dominante no seu ecossistema, o "homem rural" não passa de um elo a mais na cadeia biológica da paisagem na qual se integra e que, em parte, desorganiza. Por isso, resultam importantes as condiçōes sócio-ecnômicas e culturais, como co-participantes no panorama sanitário das comunidades.

A noção da existência de relações entre a manifestação de doenças e certos fatores ambientais chega-nos da mais remota antiguidade. Segundo as crenças animistas e fetichistas primitivas, era de mau agouro a ocorrência de fenômenos metereológicos como os eclipses, as secas e as chuvas diluviais, interpretados como avisos ou como castigo, e relacionados com a eclosão de doenças e o aparecimento de pragas.

Nos antigos escritos gregos encontram-se referências a condiçốes essenciais para a ocorrência de endemias e epidemias, mas só no tratado de Hipócrates sobre "Ares, Águas e Lugares" encontramos, reunidas, as primeiras idéias sobre ecologia médica. Águas palustres, ar confinado e mefítico e emanaçōes pútridas foram considerados como causas de enfermidades endêmicas e epidêmicas até o século passado. Ainda hoje, certas correlações entre solo, clima e doença continuam mal explicadas. E algo da teoria miasmática sobrevive no temor atual dos efeitos da poluição.

Também desce a mais remota antiguidade houve quem considerasse, como Alcméon de Crótona, saúde e doença como resultantes de forças, fatores ou atributos antagônicos, intrínsecos ou extrínsecos. Os chineses, desde o século VIII a.C., admitiam cinco elementos como os constituintes do universo; Empédocles reconhecia quatro, com os quais Faleno relacionava outros tantos humores, de cujo equilíbrio dependeriam as condições hígidas do indivíduo.

Nem sempre essas longínquas analogias podem ser consideradas como idéias germinais daquelas que, hoje, são aceitas, fundamentadas em fatos e observaçōes cientificamente válidos.

$\mathrm{O}$ aperfeiçoamento do microscópio, no século XVII, permitiu resolver a antiga disputa entre os defensores das teorias dos miasmas e do contágio, como origem da infecção. As idéias de Pasteur e as técnicas de Koch inauguraram a era da microbiologia médica, passando-se a atribuir a etiologia das doenças infecciosas à ação dos agentes patogếnicos.

Hoje reconhecemos que essa solução simplista, de unicausalidade, é incompleta.

A par da medicina clínica, desenvolveram-se práticas de higiene e saúde pública, também sobre bases empíricas. A segregação dos portadores de certas enfermidades, como a lepra, era adotada no Egito, ao 
tempo dos faraós. Grécia e Roma dispunham de obras importantes de engenharia sanitária, ainda hoje em uso. A quarentena, estabelecida como medida profilática contra o "contágio" foi regulamentada na Europa, no século XIV; e a vacinação preventiva foi usada por chineses e árabes desde muito antes de sua introdução no mundo ocidental, no século XVIII.

Entretanto, a ecologia médica só se pode desenvolver após a comprovação das teorias de Darwin e de Pasteur, e seu progresso deveu-se, em grande parte, às investigaçōes epidemiológicas sobre os ciclos complexos das zoonoses, realizadas no século $\mathrm{XX} \mathrm{e,} \mathrm{em}$ maior escala, após a Segunda Guerra Mundial.

As influências recíprocas dos organismos com os fatores físicos e bióticos do meio ambiente em que vivem determinam sua ecologia e o curso de sua evolução.

Durante o século XIX as idéias correntes sobre - processo da evolução orgânica foram sintetizadas em duas obras fundamentais, que tentaram identificar seus mecanismos de ação.

Lamarck admitia a herança de modificaçōes somáticas, de caráter adaptativo, adquiridas por influência direta do meio ambiente e em decorrência do uso mais ou menos ativo dos órgãos. Atribuía destacada importância à ação dos fatores do meio físico (ecotópicas), especialmente do clima e do substrato, sobre as plantas e animais "inferiores".

Darwin e Wallace ressaltaram, por outro lado, o papel das relações recíprocas entre organismos (alelobióticas) constituindo a seleção natural o mecanismo diretor da evolução.

Divulgador das idéias de Darwin, Ernst Haeckel considerava a adaptação e a hereditariedade como os dois princípios fundamentais da organização vital. Em 1866 propôs o termo Ecologia para designar o estudo das relaçōes dos organismos com o ambiente, o que se designava, em parte, "economia da natureza" ou, de maneira ambígua, "biologia".

Em sua essência, tanto a hipótese lamarckista quanto a teoria de Darwin baseavam-se na ação decisiva de fatores do ambiente sobre os organismos: Lamarck emprestando maior importância às condições de solo e clima e Darwin atribuindo papel prioritário à competição e cooperação entre indivíduos e espécies.

Relações com o meio físico e com a biota constituem os dois aspectos fundamentais da ecologia, e os estudos que se seguiram sobre adaptação e seleção, nas tentativas de comprovar ou refutar as duas teorias, revelaram dados que, reunidos, analisados e sintetizados, vieram a constituir os fundamentos da ecologia.

$O$ isolamento, $O$ cultivo e a identificação segura dos "agentes etiológicos", a partir dos trabalhos de 
Pasteur e de Koch, permitiram a classificação e o diagnóstico das enfermidades, de maneira mais sistemática e racional. As doenças infecciosas passaram a ser consideradas como um sistema binário, cujos fatores eram 0 agente e o paciente.

O papel dos vetores foi sugerido quando ainda não se tỉnha noção da origem biológica das infecções. Gabriel Soares de Souza, em 1587, sugeriu a transmissão da bouba por insetos. Em 1776, Montfils aventou a possibilidade de ser a brucelose transmitida por moscas, o que foi demonstrado por Raimbert, em 1869. A disseminação de parasitos, como o berne, foi descrita no início do século XVII.

Patrick Manson verificou experimentalmente a possibilidade de transmissão de doenças por insetos e, em 1978, mostrou a importância do estudo do comportamento dos parasitos nos hospedeiros interme diários, introduzindo, assim, um novo fator epidemiológico de fundamental importância ecológica.

As descobertas que se seguiram derivaram de aplicação das recomendações de Manson. Em 1895 Bruce identificava Glossina morsitans como vetor de Trypanosoma brucei, em 1881 Finlay sugeria a transmissão da febre amarela por Aedes aegypti e, em 1898, Simond demonstrava a transmissão da peste bubônica pela picada de Xenopsylla cheopis.

$\tilde{A}$ medida que o conhecimento das zoonoses se ampliava, deixando de ser domínio exclusivo da medicina veterinária para ocupar lugar de destaque na epidemiologia, delineava-se a complexidade do panorama ecológico das doenças infecciosas e parasitárias.

As tentativas de controle da peste na Îndia e da malária no Mediterrâneo mostraram o papel fundamental da taxonomia moderna na identificação segura dos vetores que realmente participam da cadeia epidemiológica. E as pesquisas sobre a nagana, na África, demonstraram a importância dos estudos da ecologia dos vetores para seu controle efetivo.

Ao mesmo tempo, aprendemos que a solução de muitos problemas sanitários esbarra, na prática, com preconceitos, crendices, hábitos e preceitos tradicionais, de natureza social ou religiosa, os quais são, por vezes, também responsáveis pela endemização de certas doenças.

Dessa maneira, além da auto-ecologia dos agentes etiológicos, vetores e hospedeiros, o estudo da ecologia das enfermidades infecciosas e parasitárias depende da pesquisa da sinecologia da transmissão.

O estudo das interaçōes de uma determinada espécie com os fatores ambientes denomina-se auto-ecologia. Cada organismo apresenta uma determinada amplitude no grau de tolerância, frente a cada fator do meio: temperatura, umidade, luz, pressão, competição. 
A existência e as características de cada associação de microorganismos, vetores e hospedeiros dependem, portanto, da superposição das áreas respectivas de distribuição geoecológica - simpatria - e da coincidência dos graus de tolerância às condições ambientais, em uma faixa comum. Focos e biótopo coincidem no espaço, mas não, necessariamente, no tempo. A correta avaliação do papel de hospedeiros não-humanos na manutenção de focos endêmicos implica, além do estudo da dinâmica de suas populações, a análise da estrutura e do funcionamento das comunidades que integra. Esse é o campo da sinecologia ou ecologia das associaçóes. É evidente que quanto maior o número de elos na cadeia epidemiológica, mais complexa se torna a ecologia da transmissấo.

O estudo da ecologia médica envolve, portanto, a elucidação de um conjunto de relações e circunstâncias, mais do que de sintomas e terapêuticas.

Nenhum organismo vive isolado na natureza, e a comunidade biótica é a unidade funcional, ao nível do ecossistema.

$\mathrm{Na}$ base de cada comunidade encontram-se os vegetais clorofilados, capazes de sintetizarem matéria orgânica a partir de elementos minerais do substrato e da energia da luz solar. Este primeiro nível trófico suporta uma pirâmide onde, sucessivamente, se superpóem os organismos fitófagos, no segundo nível; predadores primários, no terceiro; grandes predadores, no quarto; e parasitos destes, no quinto. Os microorganismos decompositores ou saprófitos fazem retornar no substrato a matéria orgânica por eles desagregada. A esse sistema dinâmico de circulação de nutrientes e transferência de energia dá-se o nome de ecossistema.

A economia da natureza é a expressão da relação que existe entre produtividade e consumo, nesse sistema.

As oportunidades abertas aos animais e plantas de distintas espécies nos ecossistemas, constituem os nichos ecológicos. Durante o curso de seu desenvolvimento ontogenético, um animal pode ocupar, sucessivamente, distintos nichos, especialmente quando sofre metamorfoses radicais. O mesmo acontece com indivíduos de sexos diferentes na cadeia trófica e, portanto, nichos distintos nos ecossistemas que integram; o mesmo acontece com mosquitos machos e fêmeas, quando são fitófagos e hematófagos, respectivamente.

Em comunidades distintas, os nichos são preenchidos por organismos pertencentes a espécies diferentes, de acordo com seus padrões de distribuição geográfica, na biosfera. Por esse motivo, o controle de pragas e parasitos exige mais que as inadequadas tentativas de erradicar os indivíduos das espécies indesejáveis. Na melhor das hipóteses, uma outra espécie insta- 
lar-se-ia no lugar da primitiva, ocupando o nicho vazio, com resultados inesperados. A solução reside na alteração do ambiente, para a supressão de determinados nichos.

$\mathrm{Na}$ investigação da ecologia das doenças infecciosas e parasitárias destacam-se dois aspectos importantes e complementares: primeiro, o estudo das relaçōes biológicas e sócio-culturais do homem com os demais elementos da comunidade biótica exógena e com os fatores do meio físico; e, em segundo lugar, a pesquisa das relações do homem com a microbiota endógena que cada indivíduo abriga.

Saúde e doença traduzem as alterações qualitativas e quantitativas que se verificam nestas microcomunidades, enquanto que determinantes sócio-econômicos e culturais ou etologicos condicionam a exposição aos fatores abióticos e microbióticos exógenos. Juntamente com o potencial genético, estes últimos são responsáveis pela história imunológica de cada indivíduo.

O equilíbrio dinâmico, homeostático, manifestase nos diferentes níveis de organização biológica, como resultado da ação dos mecanismos naturais de seleção e controle. A estabilidade ou plasticidade dos ecossistemas é um dos conceitos fundamentais da ecologia.

No nível individual, as relaçōes entre um vetor e o microorganismo que ele veicula ou transporta podem variar desde a simples relação de forésia à intimidade essencial, quando uma fase da ontogênese do microorganismo se desenvolve no corpo do hospedeiro intermediário.

As relaçōes de parasitismo, comensalismo e simbiose sugerem etapas de uma longa seqüência evolutiva, de acomodação e adaptação mútuas, durante a história filogenética dos organismos envolvidos. Entretanto, nem sempre isso se verifica, como o demonstra a variação na reação do hospedeiro à colonização. Com freqüência, a reaçāo é nula ou mínima, por parte de várias espécies.

Ao nível do ecossistema, a situação desse equilíbrio traduz-se nas epizootias ou epidemias e nas enzootias ou endemias. A condição enzoótica ou endêmica representa o estágio de adaptação alcançado através do processo de seleção natural, que elimina os hospedeiros mais suscetíveis e os microorganismos mais patogênicos, em cada comunidade biótica.

O conceito de patógeno é relativo. A patogênese depende de três fatores principais: das propriedades intrínsecas do microorganismo, da resposta do hospedeiro e das condições da infecção. A ação patogênica pode resultar da eliminação de metabolitos tóxicos para o hospedeiro; do desequilíbrio provocado pela sua introdução na microbiota individual; da sua locali- 
zação nos diferentes biótopos do corpo do hospedeiro. A resposta deste depende do local e volume do inóculo, do grau de resistência ou sensibilidade genética ou adquirida. Várias condições influem no curso da infecção, entre elas a resistência orgânica do hospedeiro, o grau de stress ou tensão a que está submetido e a variação sazonal ou circadiana da sensibilidade.

As comunidades de microorganismos endógenos distribuem-se pelos diversos biótopos disponíveis no organismo do hospedeiro, tais como aparelho digestivo, circulatório e respiratório, órgãos anexos e certas áreas protegidas da epiderme. Estas comunidades competem por espaço e alimento e cooperam de várias maneiras, em cada biótopo. A produçẫo de metabolitos com propriedades inibidoras e antibióticas e a eliminação de substâncias que preparam o ambiente para outras espécies, no processo de sucessão ecológica, condicionam a presença e a densidade dos componentes da microbiota individual. Sua distribuição microgeográfica, a associação com outros microorganismos como vírus ou fagos, a localização e rotas de dispersão no corpo do hospedeiro determinam o caráter de suas relaçōes com este. Entre a simbiose, o comensalismo e o parasitismo existe, apenas, diferença de grau e circunstância, mais que de essência.

Se, para o clínico, as infecçōes subclínicas não têm interesse, elas são de grande importância para a epidemiologia e a ecologia médica. Para estes últimos, a saúde é vista em função do equilíbrio nos ecossistemas constituídos por hospedeiros, vetores e microbiotas endógenas e exógenas. A doença é a expressāo de um desajuste nas relaçōes do hospedeiro, em seu ambiente natural, e pode ser conceituada como qualquer condição estrutural ou funcional que comprometa a sobrevivência ou prejudique o desempenho de um individuo em seu ambiente natural.

Da infecção à doença há a mesma distância que entre o comensalismo e o parasitismo.

A patologia, a clínica, a medicina ocupacional e a epidemiologia preocupam-se com os fenômenos que ocorrem, respectivamente, nos quatro níveis de complexidade da organização biológica, a saber, na célula, no indivíduo, na população e no ecossistema. Enquanto a ecologia se preocupa com a organização e funcionamento dos ecossistemas, a epidemiologia cuida dos seus aspectos sanitários.

A defasagem que se verifica entre o estado de conhecimentos sobre a ecologia e os demais aspectos relativos às doenças infecciosas e parasitárias deve-se à orientação pragmática dos currículos de medicina e acadêmica, dos de ecologia, deixando entre si uma 
"terra de ninguém", onde se manifestam os problemas sanitários que constituem o temário da ecologia médica.

A pesquisa dos componentes do complexo causal das zoonoses exige a aplicação de metodologia ecológica especial. A identificação do papel dos hospedeiros não-humanos requer o cálculo estimativo da população total de animais existentes em determinada área e o estudo de sua dinâmica populacional. Com base nesses dados, podemos estabelecer os índices reais de prevalência e incidência, na fauna. $O$ controle racional dos vetores requer o conhecimento detalhado de seus hábitos, de sua biologia e dos seus índices de densidade crítica.

A ecologia constitui, além disso, um dos pilares em que se apóia a geografia médica, freqüentemente rebaixada ao nível de mera coreografia, quando apenas mapeia a área de ocorrência das doenças, sem justificar ou explicar a razão dos padrōes pato-geográficos. Ecologia e geografia médicas constituem a base essencial para a compreensão dos mecanismos íntimos de ação das doenças infecciosas e parasitárias e para o equacionamento das medidas gerais de controle racional.

$\mathrm{E}$ evidente que, para ser efetivo e econômico, o controle deve ser integrado e deve visar o manejo dos ecossistemas, de maneira global. Tais programas devem estar a cargo de equipes interdisciplinares e precisam ter como objetivo não só a questão específica em pauta, mas a reformulação ampla do problema da integração do homem ao seu ambiente, através do planejamento de novos ecossistemas equilibrados. Não é tarefa simples, mas compensadora, a longo prazo.

Se a meta do desenvolvimento é o homem, não há por que sacrificá-lo, no processo.

\section{REFERÊNCIAS BIBLIOGRÁFICAS}

ALEXANDER, M., 1971 - Microbial Ecology. John Wiley \& Sons, N. York.

A VILAPIRES, F. D. de, 1974 - Ecologia, infecção e doença. Rev. Soc. brasil. Med. Trop., 8 (4): 235, Rio de Janeiro.

CANNON, H. L. \& H. C. Hopps, (ed.), 1971 - Environmental Geochemistry in Health and Disease. The Geol. Soc. Amer. Inc., Mem. 123, Boulder, Co.

CARPENTER, J. R., 1962 - An Ecological Glossary. Hafner Publ. Co., N, York \& London.

DAJOZ, R., 1972 - Ecologia Geral. Vozes, Petrópolis \& Ed. USP, S. Paulo.

DUBOS, R., 1965 - Man Adapting. Yale Univ. Press, N. Haven \& London.

ELTON, C. S., 1958 - The Ecology of Invasions by Animals and Plants. Methuen \& Co., London \& John Wiley, N. York.

Cadernos de Saúde Pública, RJ, 5 (2): 210-218, abr/jun, 1989 
FENNER, F. \& F. N. Ratcliffe, 1965 - Myxomatosis. Cambridge Univ. Press.

HACKET, L. W., 1937 - Malaria in Europe: an Ecological Study. London.

KORMONDY, E. J., 1965 - Readings in Ecology. Prentice-Hall, N. Jersey.

KORMONDY, E. J., 1969 - Concepts of Ecology. Prentice-Hall, N. Jersey.

LACAZ, C. S., R. G. Baruzi \& W. Siqueira Jr., (ed.), 1972 - Introdução à Geografia Médica do Brasil. Edgard Blucher, Ltda. \& Ed. USP, S. Paulo.

LE RICHE, W. H. \& J. Milner, 1971 - Epidemiology as Medical Ecology. Churchill Livingstone, Edinburgh \& London.

MARPLES, M, J., 1965 - The Ecology of the Human Skin. Thomas Springfield.

MAY, J. M., (ed.), 1958 - The Ecology of Human Disease. Studies in Medical Geography, 1. M. D. Publ., Inc., N. York.

MAY, J. M., (ed.), 1961 - Studies in Disease Ecology. Studies in Medical Geography, 2. hafner Publ. Co., N. York.

MILLS, C. A., 1939 - Medical Climatology. Charles C. Thomas, Springfield, III \& Baltimore Maryland.

MURHEAD-THOMSON, R. C., $1968-E$ cology of Insect Vector Populations. Academic Press, London \& N. York.

ODUM, E. P., 1953 - Fundamentals of Ecology. Saunders, Philadelphia \& London.

SCH WABE, C. W., 1968 - Medicina Veterinaria y Salud Pública. Org. Edit. Novaro, México.

S LADEN, B. K, 6 F. B. Bnag, (ed.), 1969 - Biology of Populations. The Biological Basis of Public Health. Amer. Elsevier Publ. Co., N. York.

SOUZA, G. S., 1938 - Tratado descriptivo do Brasil em 1587. 3: ed. Ed. Naconal, S. Paulo.

SUSSER, M. W. \& W. Watson, 1971 - Sociology in Medicine. Oxford univ. Press, London, N. York \& Toronto. 